\title{
Transient Elastohydrodynamic Lubrication Analysis of Spur Gear Running-in Considering Effects of Solid Particles
}

\author{
X.B. Huang \\ School of Mechanical Engineering \\ Qingdao Technological University \\ Qingdao, China \\ Y.Q. Wang \\ School of Mechanical Engineering \\ Qingdao Technological University \\ Qingdao, China
}

\author{
Q. Liu \\ School of Mechanical Engineering \\ Qingdao Technological University \\ Qingdao, China \\ N. Dong \\ School of Mechanical Engineering \\ Qingdao Technological University \\ Qingdao, China
}

\begin{abstract}
The elastohydrodynamic lubrication model considering solid particles was set up. Taking effect of solid particles into account, the Reynolds equation was deduced. The elastohydrodynamic lubrication analysis of spur gear running-in was completed considering time-variant effect. Results show that oil film pressure in region 2 where particle is located increases dramatically but oil film thickness in region 2 decreases thinking about effects of solid particles. When particle size becomes greater oil film pressure increases obviously, oil film thickness diminishes. The minimum film thickness and maximum film pressure both diminish considering effects of solid particles.
\end{abstract}

Keywords-solid particles; spur gears; running-in; time-variant effect; elastohydrodynamic lubrication

\section{INTRODUCTION}

Gearing is the most common mechanical transmission. Before normaluse of generated gears, they must be tested in running-in process. Qualified gears are approved to be released from factories. The efficiency and quality of running -in process have significant influence on operation efficiency and service life of gears. Therefore, doing researches about lubrication mechanism of gears in running-in process is quite meaningful. A large number of experiments and theoretical researches on gears running-in have been done by relevant scholars at home and abroad. Cas tro.J,et al[1] establis hed mixed film lubrication model and analyzed the change of normal stress and shear stress at meshing points on gears meshing line. In addition, why debris may appear in lubricating oil was interpreted. Bentley.J.A,et al[2] discussed the importance of lubricating oil on industry gears in running-in process, the effects of compounded lubricating oil, extreme pressure lubricating oil and synthetic oil on gears lubrication in running-in process, respectively. The influence of solid particles on lubrication mechanism of gears in running-in process was not considered in all studies above. XIE,et al[3] set up elastohydrodynamic lubrication model of grease lubrication under line contacts considering solid particles, lubrication equation was revised and the effects of different sizes, locations and velocities of solid particles on oil film pressure and film thickness were analyzed. However, effects of solid particles on oil lubrication of gears were not taken into account. The author will revise Reynolds equation considering solid particles. The changes of film pressure and film thickness of spur gears in running-in process will be analyzed deeply taking solid particles, time-variant effect, load and rotate velocity into consideration.

\section{MATHEMATICAL MODEL}

Revised Reynolds equation considering solid particle can be described as .

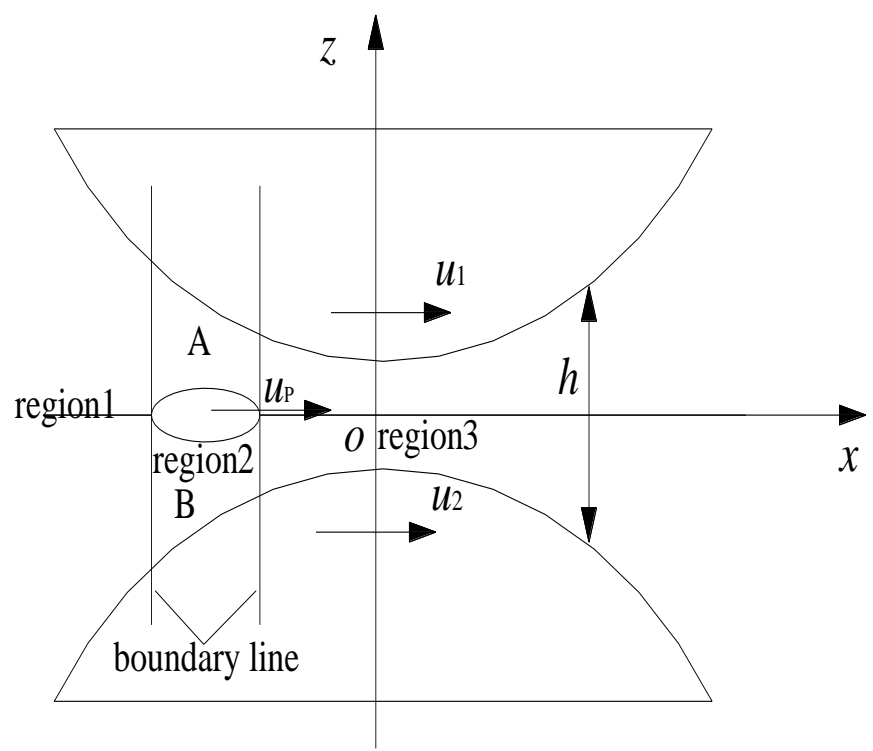

FIGUREI. CONT ACT AREA CONT AINING SOLID PARTICLE ELAST OHYDRODYNAMIC LUBRICATION MODEL. 


\section{Lubrication equation in region 1 and region 3}

For derivation process details see Numerical Analysis of Fluid Lubrication[4], is othermal Reynolds equation of infinite long term contact:

$$
\frac{\partial}{\partial x}\left(\frac{\rho h^{3}}{\eta} \frac{\partial p}{\partial x}\right)=12 \frac{\partial}{\partial x}(\rho u h)+12 \frac{\partial(\rho h)}{\partial t}
$$

\section{Lubrication equation in region 2}

As Figure 1 shows that region 2 cons ists of $\mathrm{A}$ and $\mathrm{B}, \mathrm{z} 0$ is half size of solid particle on zaxis direction, for $\mathrm{A}$ and $\mathrm{B}$, according to infinitesimal body of lubricating oil film force balance condition:

$$
\frac{\partial p}{\partial x}=\frac{\partial \tau_{x}}{\partial z}
$$

Newton law of viscosity can lead to $\tau_{x}=\eta \frac{\partial u}{\partial z}$, substituted into Eq.(2) Eq.(3) can be achieved.

$$
\frac{\partial p}{\partial x}=\frac{\partial}{\partial z}\left(\eta \frac{\partial u}{\partial z}\right)
$$

Since $\mathrm{p}$ and $\eta$ is not the function of $\mathrm{z}$, calculating indefinite integral about $\mathrm{z}$ on both sides of Eq. (3) yields

$$
\eta \frac{\partial u}{\partial z}=\frac{\partial p}{\partial x} z+C_{1}
$$
yields

Calculating indefinite integral about zon both sides of Eq. (4)

$$
u=\frac{1}{2 \eta} \frac{\partial p}{\partial x} z^{2}+\frac{C_{1}}{\eta} z+\frac{C_{2}}{\eta}
$$

Substituting boundary conditions of A described as $z=z_{0}, u=u_{p} ; z=\frac{h}{2}, u=u_{1}$

$$
C_{1}=\frac{\eta\left(u_{1}-u_{\mathrm{p}}\right)}{\frac{h}{2}-z_{0}}-\frac{1}{2} \frac{\partial p}{\partial x}\left(\frac{h}{2}+z_{0}\right), C_{2}=\frac{\eta\left(z_{0} u_{1}-\frac{h u_{\mathrm{p}}}{2}\right)}{z_{0}-\frac{h}{2}}+\frac{h z_{0}}{4} \frac{\partial p}{\partial x}
$$

Oil lubricant flow in $\mathrm{A}$ is denoted by $q_{x \mathrm{~A}}$, $q_{x \mathrm{~A}}=\int_{z_{0}}^{\frac{h}{2}} u d z$,substituting $C_{1}, C_{2}$ into Eq.(5) yields

$$
q_{x \mathrm{~A}}=-\frac{1}{12 \eta} \frac{\partial p}{\partial x}\left(\frac{h^{3}}{8}-z_{0}^{3}\right)+\frac{h z_{0}}{8 \eta} \frac{\partial p}{\partial x}\left(\frac{h}{2}-z_{0}\right)+\frac{u_{1}+u_{p}}{2}\left(\frac{h}{2}-z_{0}\right)
$$

Substituting boundary conditions of B described as

$$
\begin{gathered}
z=-\frac{h}{2}, u=u_{2} ; z=-z_{0}, u=u_{p} \\
\text { into Eq. (5) yields } \\
C_{1}=\frac{\eta\left(u_{2}-u_{\mathrm{p}}\right)}{z_{0}-\frac{h}{2}}+\frac{1}{2} \frac{\partial p}{\partial x}\left(\frac{h}{2}+z_{0}\right), C_{2}=\frac{\eta\left(z_{0} u_{2}-\frac{h u_{\mathrm{p}}}{2}\right)}{z_{0}-\frac{h}{2}}+\frac{h z_{0}}{4} \frac{\partial p}{\partial x}
\end{gathered}
$$

Oil lubricant flow in $\mathrm{B}$ is denoted by $q_{x \mathrm{~B}}$, $q_{x \mathrm{~B}}=\int_{-\frac{h}{2}}^{-z_{0}} u d u$,substituting $C_{1}, C_{2}$ into Eq.(5) yields

$$
q_{x \mathrm{~B}}=-\frac{1}{12 \eta} \frac{\partial p}{\partial x}\left(\frac{h^{3}}{8}-z_{0}^{3}\right)+\frac{h z_{0}}{8 \eta} \frac{\partial p}{\partial x}\left(\frac{h}{2}-z_{0}\right)+\frac{u_{2}+u_{p}}{2}\left(\frac{h}{2}-z_{0}\right)
$$

Totalflow in region 2 is denoted by $q_{x}, q_{x}=q_{x \mathrm{~A}}+q_{x \mathrm{~B}}$, it can be calculated as

$$
q_{x}=-\frac{1}{48 \eta} \frac{\partial p}{\partial x}\left(h-2 z_{0}\right)^{3}+\left(h-2 z_{0}\right) \frac{u_{1}+u_{2}+2 u_{p}}{4}
$$

Fluid mass in region 2 is denoted by $m_{x}, m_{x}=\rho q_{x}$,substituting $m_{x}$ into equation of continuity after integral[5] yields

$$
\frac{\partial m_{x}}{\partial x}+\frac{\partial(\rho h)}{\partial t}=0
$$

The is othermal Reynolds equation considering solid particle can be expressed as follows

$$
-\frac{\partial}{\partial x}\left[\frac{\rho\left(h-2 z_{0}\right)^{3}}{48 \eta} \frac{\partial p}{\partial x}\right]+\frac{\partial}{\partial x}\left[\rho\left(h-2 z_{0}\right) \frac{u_{1}+u_{2}+2 u_{p}}{4}\right]+\frac{\partial\left[\rho\left(h-2 z_{0}\right)\right]}{\partial t}=0
$$

\section{BASIC EQUATIONS}

Reynolds equation in region 1 and 3 is Eq. (1). Reynolds equation in region 2 where solid particles settles is Eq. (7). The load equation, film thickness equation, viscosity-pressure relationship and density-pressure relationship for details see Numerical Analys is of Fluid Lubrication [4].Each equation and its boundary conditions need to be nondimensionalized. The dimensionless parameters are defined as follows:

$$
\begin{aligned}
& X=x / b, \quad W_{0}=w_{0} /\left(E R_{0}\right), \quad U_{0}=\eta_{0} u_{0} /\left(E R_{0}\right), \\
& \bar{h}=h R_{0} / b^{2}, P=p / p_{\mathrm{H}}, \bar{\eta}=\eta / \eta_{0}, \bar{\rho}=\rho / \rho_{0}, \\
& C_{R t}=R / R_{0}, C_{u t}=u / u_{0}, C_{w t}=w / w_{0}, \stackrel{,}{t}=t u_{0} / b \text {; }
\end{aligned}
$$


Where $w_{0}$ is reference load and $\mathrm{w}$ is practical load, $\mathrm{b}$ is half of Hertz contact width of both rigid teeth when loaded by $w_{0}$, $b=\sqrt{8 w_{0} R_{0} /(\pi E)}, p_{\mathrm{H}}$ is the maximumHertzpressure when loaded by $w_{0}, p_{\mathrm{H}}=E b /\left(4 R_{0}\right), \rho_{0}$ and $\eta_{0}$ denote lubricant environmental density and environmental viscosity respectively, $C_{w t}, C_{R t}, C_{u t}$ denote load time-variant coefficient, comprehensive radius of curvature time-variant coefficient and speed time-variant coefficient respectively, $R_{0}$ is reference radius of curvature, $R_{0}=R_{b a} R_{b b} \tan \varphi /\left(R_{b a}+R_{b b}\right), R_{b a}$ and $R_{b b}$ denote base radius of gear 1 and gear 2 respectively, $\varphi$ is reference circle angle, $\mathrm{R}$ is comprehensive radius of curvature of meshing point, $R=R_{1} R_{2} /\left(R_{1}+R_{2}\right)$, $R_{1}=R_{b a} \tan \varphi-s, R_{2}=R_{b b} \tan \varphi+s_{, \mathrm{S}}$ is the distance between meshing points and pitch points, ${ }^{u_{0}}$ is the entrainment velocity of pitch point, $\mathrm{u}$ is entrainment velocity of meshing points, $u=\left(u_{1}+u_{2}\right) / 2, u_{1}=\omega_{1} R_{1}, u_{2}=\omega_{2} R_{2}, \omega_{1}$ and $\omega_{2}$ denote rotational velocity of two gears respectively, $\mathrm{h}$ is film thickness.

\section{NUMERICAL APPROACHES}

Multi-grid method can be applied to completing pressure solution. Multiple grid integration method can be used to calculate elastic deformation. W circle is adopted in computation. There are six layers gridding, the most dense layer locates 961 nodes. The transient before meshing into point is handled as steady state. There are 120 transients from meshing into points to recess action points. The convergence criterion is that transient pressure and load's relative errors must be lesser than $10^{-3}$.

\section{RESULTS AND DISCUSSIONS}

Table 1 is the list of lubrication relevant parameters. Figure 2 is variation diagram of load along with line of action, in which A 、 B 、 C 、 D 、 E are five transients of time-variant load. Velocity of solid particles is 0 and dimensionless centre coordinate of solid particles in $\mathrm{x}$ direction $\mathrm{XC}=-0.13$.

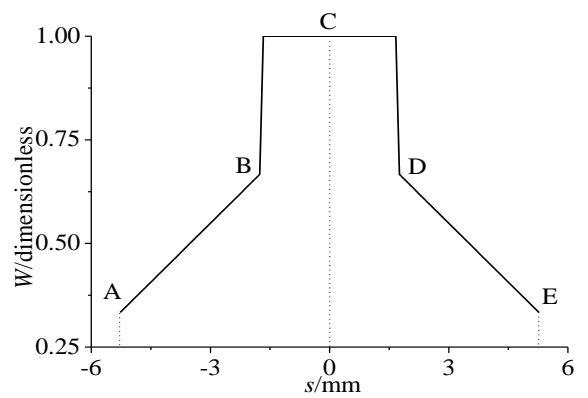

FIGUREII. LOAD ALONG WITH LINE OF ACTION VARIATION DIAGRAM.
T ABLEI. LUBRICATION RELEVANT PARAMETERSLIST.

$\begin{array}{cc}\text { oil viscosity } \eta_{0}(\mathrm{~Pa} \cdot \mathrm{s}) & 0.075 \\ \text { viscosity-pressure coefficient } \alpha\left(\mathrm{Pa}^{-1}\right) & 2.19 \times 10^{-8} \\ \text { oil environmental } & 870 \\ \text { density } \rho_{0}\left(\mathrm{~kg} \cdot \mathrm{m}^{-3}\right) & \\ \text { gears density } \rho_{1,2}\left(\mathrm{~kg} \cdot \mathrm{m}^{-3}\right) & 7850 \\ \text { Young modulus } E_{1,2}(\mathrm{~Pa}) & 2.06 \times 10^{11} \\ \text { Poisson ratio } v_{1,2} & 0.3 \\ \text { number of teeth } \mathrm{z}_{1}, \mathrm{z}_{2} & 35,140 \\ \text { module } m(\mathrm{~mm}) & 2 \\ \text { rotate velocity of pinion } n_{1}(\mathrm{r} / \mathrm{min}) & 1500 \\ \text { tooth width } B(\mathrm{~mm}) & 20 \\ \text { gear pressure angle } \varphi\left({ }^{\circ}\right) & 20 \\ \text { transmitted power } P(\mathrm{~kW}) & 10 \\ \text { addendum coefficient } h^{*} \text {,teeth gap } & 1.0,0.25 \\ \quad \text { coefficient } c^{*} & \\ \text { dimensionless position coordinate of } \\ \text { particles } X_{\mathrm{C}}\end{array}$

A. The Effects of Solid Particles on Oil Film Pressure and Film Thickness Comparing With None

Figure 3 is oil film pressure and film thickness distribution diagram. A significant increase of oil film pressure in region 2 where solid particles settles can be seen from Figure 4 .Film thickness decreases considering solid particles and film necking position is closed to export zone.

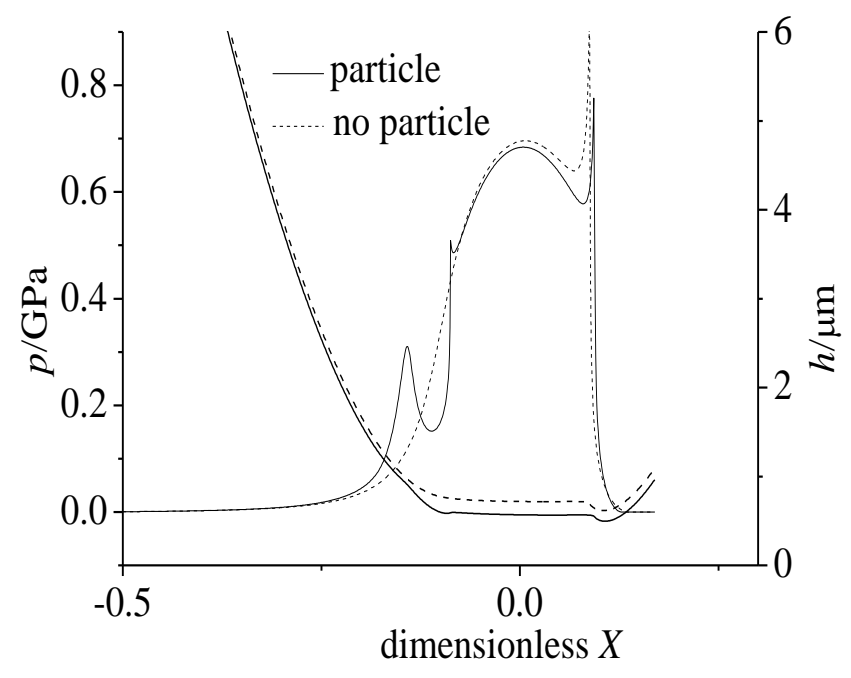

FIGUREIII. OIL FILM PRESSURE AND FILM THICKNESS DISTRIBUTION DIAGRAM.

\section{B. Effects of Solid Particles Sizes on Oil Film Pressure and Film Thickness}

Figure 4 consists of (a) and (b) that are oil film pressure and film thickness distribution diagrams considering different sizes of solid particles (studied particles are spherical particles, SR0.01 indicates that dimensionless radius is 0.01 ). From (a) can be seen 
that the minimum size of particles has negligible influence on oil film pressure, on contrary, the maximum size of particles causes the greatest rise in film pressure. Hence, a conclusion can be drawn that larger size of particles may cause more distinct rise in film pressure. From (b) can be seen that if radius of spherical particles becomes greater film thickness diminishes.

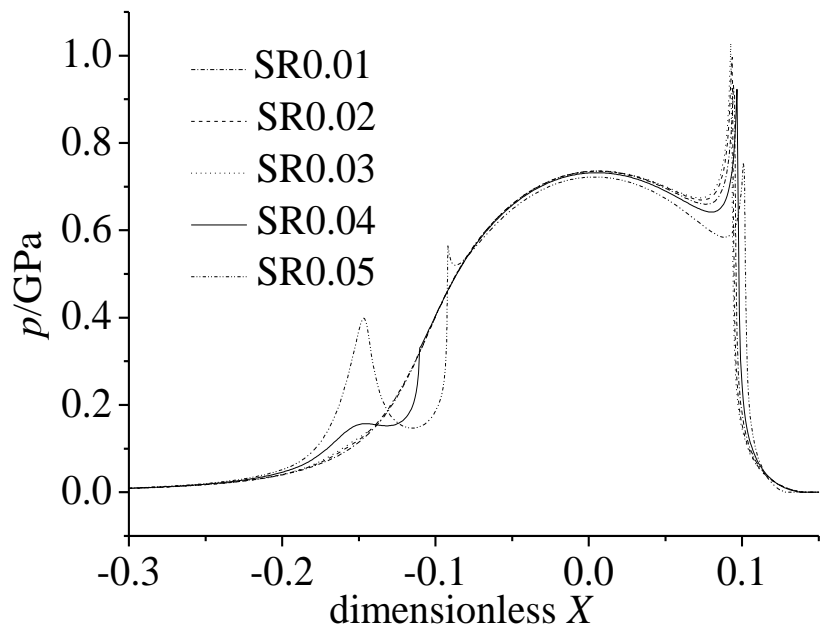

(a) Film pressure distribution diagram

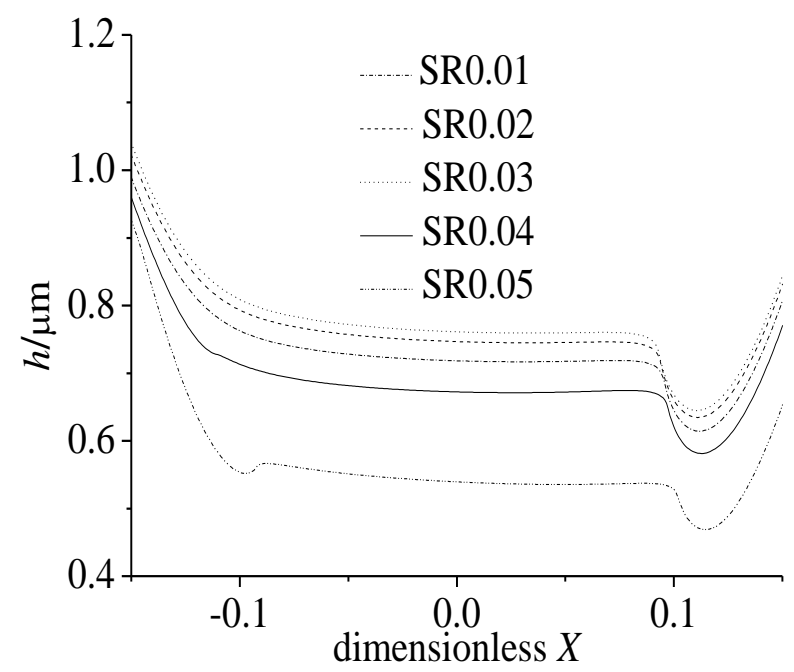

(b) Film thickness distribution diagram

FIGUREIV. OIL FILM PRESSURE AND FILM THICKNESS VARIATION DIAGRAM.

\section{Effects of Solid Particles on Oil Film Pressure and Film Thickness under Time-Variant Effect}

Figure 5 consists of (a) and (b) that are transient film pressure and transient film thickness distribution diagrams considering influence of solid particles. From (a) can be seen that oil film pressure in the entrance region considering solid particles becomes greater. From(b) can be seen that film necking position moves to export zone first and then come back to entrance region.

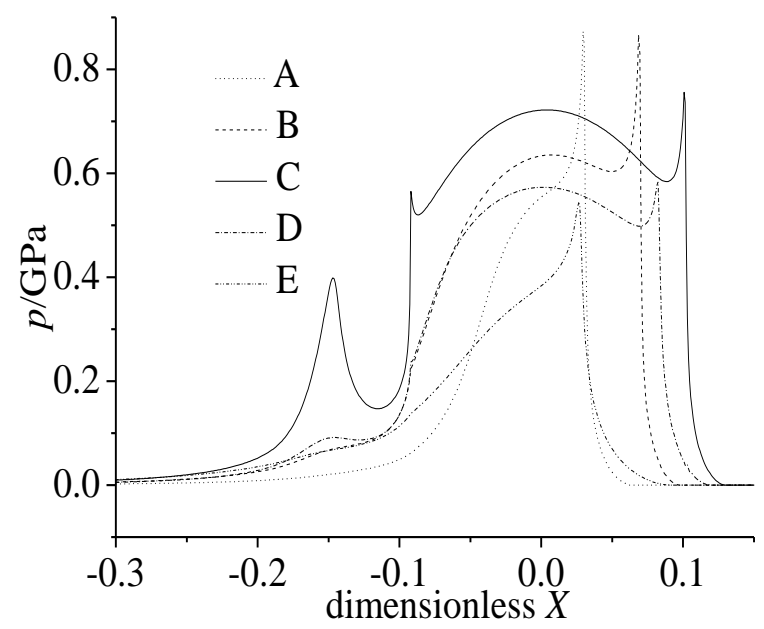

(a) Film pressure distribution diagram

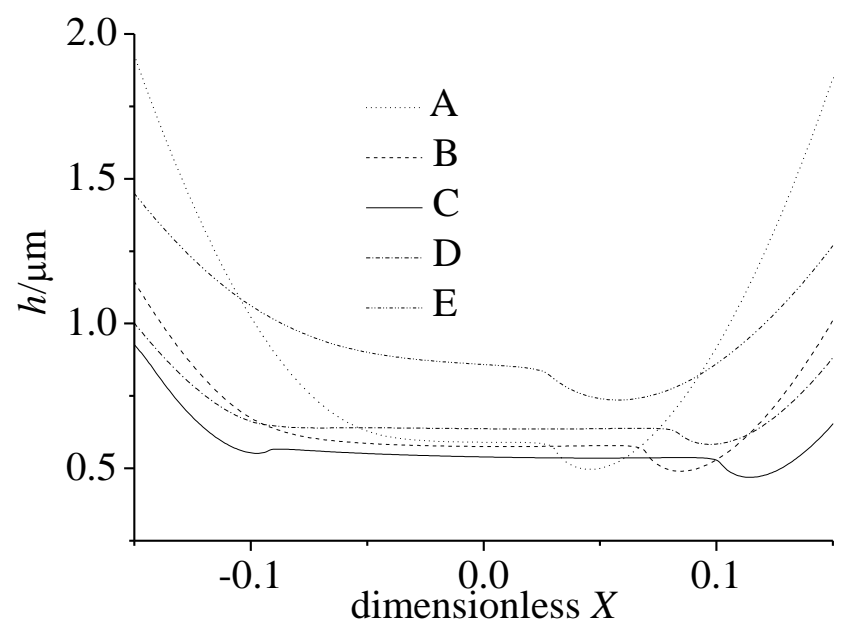

(b) Film thickness distribution diagram

FIGUREV. OIL FILM PRESSURE AND FILM THICKNESS VARIATION DIAGRAM.

\section{Effects of Solid Particles on Minimum Film Thickness and Maximum Film Pressure}

Figure 6 consists of (a) and (b) that are the minimum film thickness and the maximum film pressure distribution diagram considering solid particles. From (a) can be seen that the minimumfilmthickness decreases when solid particles are taken into consideration. From (b) can be seen the maximum film pressure also decreases considering solid particles. 


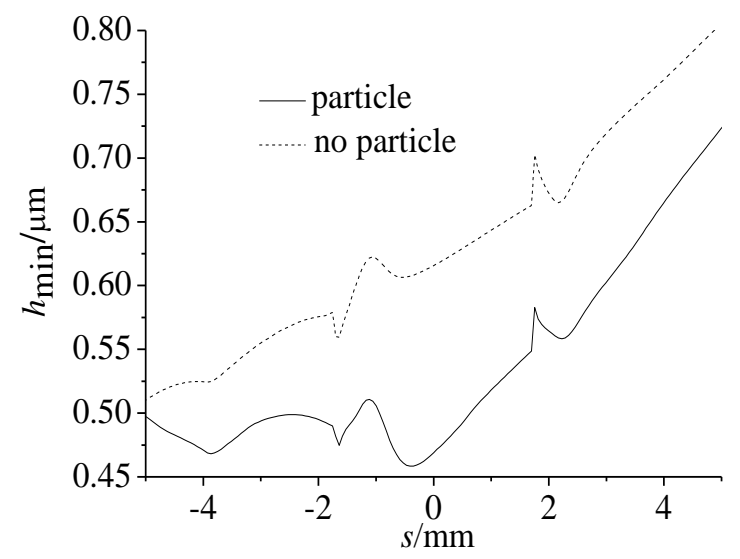

(a) Minimum film thickness variation diagram

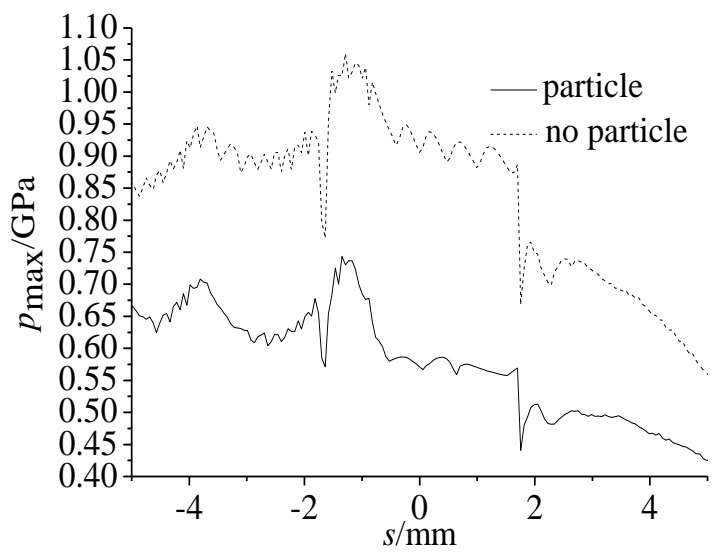

(b) Maximum film pressure variation diagram

\section{FIGUREVI. MINIMUM FILM THICKNESS AND MAXIMUM FILM PRESSURE DIST RIBUTION DIAGRAM.}

\section{CONCLUSIONS}

(1) The film pressure in region 2 where solid particles are located increases dramatically and the film thickness in region 2 decreases considering sold particles. The film pressure changes remarkably with increases in size of solid particles. If radius of spherical particles becomes larger film thickness in contact area will be thinner. Moreover, increase in radius of spherical particles can result in distinct decrease in film thickness in region 2.

(2) The minimum film thickness and maximum film pressure decrease taking solid particles and time-variant effect into account.

\section{ACKNOWLEDGEMENT}

The project was supported by the National Natural Science Foundation of China (51175275) and Qingdao Technology Project(12-1-4-4-(2)-jch).

\section{REFERENCES}

[1] Castro J, Seabra J. Global and local analysis of gear scuffing tests using a mixed film lubrication model[J]. Tribology International, 2008, 41(4): 244-255.
[2] Bentley J A, Korane K J. Lubes Ensure Slick-Running Gears[J]. Machine Design, 1995, 67(9): 95-97.

[3] XIE X P, PENG Z L, CHEN S L. Numerical Analysis of Influence of Solid Particles on Elastohydrodynamic Line Contacts under Grease Lubrication[J]. Journal of South China University of Technology (Natural Science Edition),2012,7:011.

[4] YANG P R. Numerical Analysis of Fluid Lubrication[M]. Beijing: National Defence Industry Press, 1998. 